Marquette University

e-Publications@Marquette

College of Nursing Faculty Research and

Publications

Nursing, College of

9-1-2017

\title{
Ethics in Practice: From Moral Distress to Moral Resilience
}

Kathryn Schroeter

Marquette University, kathryn.schroeter@marquette.edu

Accepted version. Journal of Trauma Nursing, Vol. 24, No. 5 (September/October 2017): 290-291. DOI. (C) 2017 Society of Trauma Nurses. Used with permission.

Kathryn Schroeter was affiliated with Froedtert Hospital and Medical College of Wisconsin at the time of publication. 


\title{
Marquette University
}

\section{e-Publications@Marquette}

\section{Nursing Faculty Research and Publications/College of Nursing}

This paper is NOT THE PUBLISHED VERSION; but the author's final, peer-reviewed manuscript. The published version may be accessed by following the link in th citation below.

Journal of Trauma Nursing, Vol. 24, No. 5 (September/October 2017)): 290-291. DOI. This article is (C) Society of Trauma Nurses and permission has been granted for this version to appear in ePublications@Marquette. Society of Trauma Nurses does not grant permission for this article to be further copied/distributed or hosted elsewhere without the express permission from Society of Trauma Nurses.

\section{Ethics in Practice: From Moral Distress to Moral Resilience}

\author{
Kathryn Schroeter \\ Froedtert Hospital and Medical College of Wisconsin, Milwaukee, Wisconsin.
}

Nurses have been dealing with ethical issues and dilemmas in practice for years, and many of have experienced moral distress along the way. Moral distress is the condition of knowing the morally right thing to do, but institutional, procedural, or social constraints make doing the right thing nearly impossible and threaten our core values and moral integrity ( $\frac{\text { American Nurses Association [ANA], } 2015}{1}$, p. 44). Much has been written about moral distress, especially regarding the impact that it has on individual health care providers as well as on patient care quality.

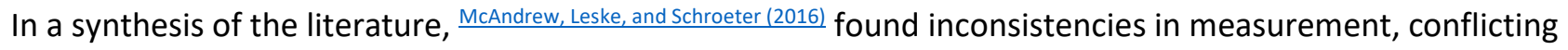
findings of moral distress and nurse demographics, problems with the professional practice environment, difficulties with communication during end-of-life decisions, compromised nursing care as a consequence of moral distress, and few effective interventions.

From a personal perspective, the experience of moral distress can develop into something that is emotionally painful, with associated feelings of one's personal and professional integrity being compromised. There is an accompanying need to bring resolution to the issue so as to be able to move on from it, which brings me to the concepts of moral residue, moral courage, and moral resilience. My previous description of my experience is an

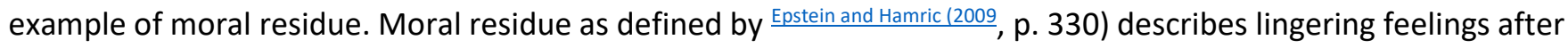


a morally problematic situation has passed; in the face of moral distress, the individual feels as if seriously compromising himself or herself, or allowed others to be compromised, resulting in loss of moral integrity.

Moral courage is the capacity of an individual to overcome fear and stand up for his or her core values; the willingness to speak out and do what is right in the face of forces that would lead a person to act in some other way; it puts principles into action (Lachman, 2007, p. 131). Moral courage supports nurses as advocates, both for themselves and for their patients. Acts of conscientious objection are acts of moral courage $\left(\frac{\mathrm{ANA}, 2015}{,}, \mathrm{p} .21\right)$. The act of advocacy implies taking some sort of action on behalf of some person, some principle, some belief, some policy, and so on. It means putting yourself on the line, so it is important to be able to articulate your position effectively. When nurses have difficulty articulating the reasons why they object to something, it can impact their moral courage. It becomes imperative for nurses to have knowledge and support for their arguments. This is where the ANA Code of Ethics for Nurses can help ( $\left(\mathrm{ANA}^{2015}\right)$. The provisions in the code serve as the information, direction, and support for nurses when composing a moral stand. The Code is there to support and guide our practice-We just have to read it and use it.

However, even if we have moral courage, we may still feel emotionally exhausted from dealing with ethical issues in practice. We are familiar with the resiliency of our patients as they cope with disease and injury. However, we, as nurses, also need to develop a type of resiliency when dealing with ethical issues and dilemmas. We need a type of moral resiliency. Moral resiliency has been defined as the ability and willingness to speak and take right and good action in the face of an adversity that is moral/ethical in nature ( $\frac{\text { Lachman, } 2016}{}, \mathrm{p}$. 122). Our work environment needs not only a culture of safety but also an ethical culture-a culture of civility and respect. Yet, although we strive to secure such cultures of our environments, we must still work to develop such strengths as moral courage and moral resilience.

Recently, the ANA's Center for Ethics and Human Rights convened a Moral Resilience Professional Issues Panel. This panel has been designed with the purpose of addressing the phenomenon of moral distress and to develop policy and identify strategies to strengthen moral resilience within practicing nurses. The panel will conduct its work over a 6-month period in 2017. The Moral Resilience Professional Issues Panel is working on the following goals: identifying a current understanding of moral distress in practicing nurses (including but not limited to hospital, long-term care, education, administration, research); identifying current and potential strategies to strengthen moral resilience; assessing current availability and scalability of resources that contribute to moral resilience; identifying strategies that could strengthen the "ethical voice" of nurses across care settings; and establishing goals to strengthen moral resilience.

The ANA often solicits public comment on issues, events, position statements, policies, and so on. Nurses need to participate in these forums so that we can work together to become stronger, more effective practitioners. I encourage you all to review the ANA website and participate in providing direction for our practice. As trauma nurses, we represent a group that deals with ethical issues and moral distress as a part of our practice environment. We also use our professional nursing organizations to support our practice. We are strong practitioners, but we can be stronger if we continue to develop our moral resilience.

According to $\frac{\text { Rushton (2017 }}{2}$, p. S13), we, as nurses, need to shift our narrative-from one of distress and depletion to one of solutions and possibilities - and this shift can be achieved by cultivating moral resilience, which is now defined as a person's capacity to sustain, restore, or deepen her or his integrity in response to moral complexity, confusion, distress, or setbacks. We know that we work in environments of moral complexity, and now we must do what we can to develop our moral resiliency and promote the best practice environments possible. 


\section{REFERENCES}

American Nurses Association (ANA). (2015) Code of ethics for nurses with interpretive statements. Silver Springs, MD: Author.

Epstein E. G. Hamric A. B. (2009). Moral distress, moral residue, and the crescendo effect. Journal of Clinical Ethics, 20(4), 330-342.

Lachman V. D. (2007). Moral courage: A virtue in need of development? Medsurg Nursing, 16(2), 131-133.

Lachman V. D. (2016). Moral resilience: Managing and preventing moral distress and moral residue. Medsurg Nursing, 25(2), 121-124.

McAndrew N., Leske J., Schroeter K. (2016). Moral distress in critical care nursing: The state of the science. Nursing Ethics, 23(6), 1-19.

Rushton C. H. (2017). Cultivating moral resilience. AJN American Journal of Nursing, 117(2), S11-S15. 